\title{
Research Paper: Hydroalcoholic Extract of Anchusa Italica Protects Global Cerebral Ischemia-Reperfusion Injury Via a Nitrergic Mechanism
}

\author{
Samira Asgharzade ${ }^{1} \odot$, Robert D. E. Sewell ${ }^{\circledR}$, Zahra Rabiei ${ }^{3}$, Fatemeh Forouzanfar ${ }^{4,5} \oplus$, Sedigheh Kazemi Sheikhshabani ${ }^{1}$, Mahmoud \\ Rafieian-Kopaei ${ }^{3 *}$ (10
}

1. Cellular and Molecular Research Center, Basic Health Sciences Institute, Shahrekord University of Medical Sciences, Shahrekord, Iran.

2. Cardiff School of Pharmacy and Pharmaceutical Sciences, Cardiff University, Cardiff, CF10 3NB. Wales, U.K.

3. Medical Plants Research Center, Basic Health Sciences Institute, Shahrekord University of Medical Sciences, Shahrekord, Iran

4. Neuroscience Research Center, Mashhad University of Medical Sciences, Mashhad, Iran.

5. Department of Neuroscience, Faculty of Medicine, Mashhad University of Medical Sciences, Mashhad, Iran.

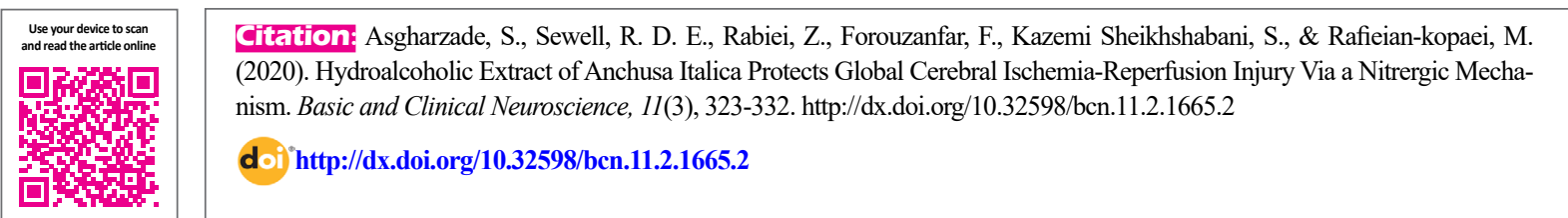

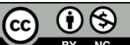

Article info:

Received: 11 Feb 2019

First Revision: 12 Mar 2019

Accepted: 20 Jul 2019

Available Online: 01 May 2020

Keywords:

Anchusa italica, Ischemiareperfusion, Nitric oxide, Stroke

\section{A B S T RA C T}

Introduction: In stroke models, Inducible Nitric Oxide Synthase (iNOS) expression initiates cellular toxicity due to excessive Nitric Oxide (NO) generation. Anchusa italica is a medicinal herb with anti-inflammatory, antioxidant and neuroprotective properties. This study evaluated the antioxidant activity and NOS mRNA expression of the Hydroalcoholic Extract Of Anchusa Italica (HEAI) in an experimental stroke model in rats.

Methods: The stroke model was induced by bilateral occlusion of both common carotid arteries for $60 \mathrm{~min}$. Twenty-four hours after surgery, HEAI (50 and $100 \mathrm{mg} / \mathrm{kg}$ i.p.) was injected daily for 10 consecutive days. mRNA expression levels of NOS subtypes and hippocampal Brain-Derived Neurotrophic Factor (BDNF) were studied using real-time PCR. Besides, hippocampal tissue plus serum concentrations of NO and Malondialdehyde (MDA) were measured.

Results: HEAI decreased MDA in both serum and hippocampal tissue and also reduced serum NO levels. Additionally, in the HEAI-treated groups, a down-regulation of iNOS mRNA expression, and an up-regulation of BDNF mRNA expression were observed.

Conclusion: The results indicated that the administration of HEAI even after the onset of ischemia protects the brain from free radical injury and inflammation via a down-regulation of iNOS expression inhibiting NO production and an up-regulation of BDNF mRNA.

\section{* Corresponding Author:}

Mahmoud Rafieian-Kopaei, PhD.

Address: Medical Plants Research Center, Basic Health Sciences Institute, Shahrekord University of Medical Sciences, Shahrekord, Iran.

Tel: +98 (38) 13330709

E-mail: rafieian@yahoo.com 


\section{Highlights}

- Nitric oxide synthase types include endothelial (eNOS), neuronal (nNOS), and inducible (iNOS) types.

- Both nNOS and iNOS have deleterious effects on neurons in the ischemic brain.

- BDNFis a neurotrophic factor promoting synaptic plasticity and neuronal survival.

- Anchusa italic reduced iNOS but increased BDNF mRNA expression in a stroke model.

- A. italica is an anti-inflammatory/antioxidant herb with neuroprotective properties.

\section{Plain Language Summary}

Transient global cerebral ischemia can develop clinically. Cerebral blood vessel reperfusion may also augment brain damage and this is known as cerebral Ischemia-Reperfusion (I-R) injury. Nitric Oxide (NO) is a neurotransmitter involved in the formation of hippocampal memory and exerts its beneficial effects when it is synthesized at physiological concentrations in the brain. However, enhanced levels of NO can alter its physiological neuromodulator role to a nervedamaging agent leading to induce inflammation. Antioxidants reduce the actions of unstable harmful oxygen-containing reactive molecules (reactive oxygen species) to protect nerve cells from I-R-induced damage in animal models. The medicinal plant, Anchusa italica, is a useful source of antioxidants that offers possible protection against global cerebral ischemia and reperfusion injury. Our findings showed that A. Italic decreases oxidative stress by down-regulating inducible nitric oxide synthase (iNOS) mRNA expression, and up-regulating the mRNA expression of Brain-Derived Neurotrophic Factor (BDNF), which boosts the survival of nerve cells during I-R.

\section{Introduction}

I

schemic stroke is the most prevalent type of stroke and a leading cause of adult disability and mortality worldwide (Bart van der Worp \& van Gijn, 2007). Transient global cerebral ischemia can occur clinically, starving brain tissue of blood even temporarily to instigate the death of neuronal cells (Peng et al., 2012). Cerebral blood vessel reperfusion may also augment brain damage and this is known as cerebral Ischemia-Reperfusion (I-R) injury (Peng et al., 2012).

Multiple and complex factors, including oxidative, excitotoxic, and nitrosative stress, infarct depolarization, inflammation, and apoptosis-like mechanisms may well lead to more serious damage and cell death in cerebral ischemic stroke (Prentice, Modi, \& Wu, 2015).

NO is a putative peripheral and central neurotransmitter, which is generated by three different subtypes of Nitric Oxide Synthases (NOSs), namely neuronal NOS (nNOS), endothelial NOS (eNOS), and inducible NOS (iNOS) (Cui et al., 2013). Hippocampal nNOS and eNOS are plentiful and have an important role in learning and memory processes implicated in behavioral phenomena, such as inhibition of passive avoidance and spatial learning (Harooni, Aghdi, Sepehri, \& Haeri Rohani, 2009). $\mathrm{NO}$ is involved in the formation of hippocampal shortand long-term memory and it has been shown that NOS inhibitors impair memory performance in both chicks and mice (Smith et al., 2016). Moreover, the NO generated after N-methyl-D-aspartate (NMDA) receptor stimulation also behaves as a retrograde messenger producing hippocampal long-term potentiation (Paul \& Ekambaram, 2011). However, NO exerts all its positive learning and memory effects when it is generated at natural physiological concentrations (Paul \& Ekambaram, 2011).

iNOS is unregulated after I-R injury and generates excessive NO, which reacts with superoxide to form peroxynitrite radical causing neuronal death. Due to its high rate of oxidative metabolic activity, the brain is vulnerable to oxidative stress, intense production of Reactive Oxygen Species (ROS), and a high content of polyunsaturated fatty acids. It also has a marginal antioxidant capacity, minimal reparative activity, and a non-replicating nature within neuronal cells (Liu, Li, Zhao, Wang, Qu, \& Mu, 2015). Enhanced levels of NO may alter its physiological neuromodulatory role to neurotoxic agents inducing neuronal inflammation and demyelination, memory impairment and neurodegeneration (Paul \& Ekambaram, 2011). 
In contrast, eNOS confers beneficial effects during cerebral ischemia (Zeng et al., 2011). Thus, eNOS can lessen acute ischemic injury and promote recovery following cerebral ischemia by regulating cerebral blood flow, maintaining cerebral homeostasis and exerting an antiinflammatory activity (Chen, Ivy, \& Russo-Neustadt, 2006; Chen, Cui, Zacharek, Roberts, \& Chopp, 2009). Moreover, eNOS up-regulates the expression of BrainDerived Neurotrophic Factor (BDNF) (Cui et al., 2013). BDNF is a key neurotrophic factor, which not only promotes synaptic plasticity but also neuronal survival and it has an integral role in certain forms of learning and memory. Hence, up-regulating BDNF may well decrease or prevent cell damage following transient forebrain ischemia and reduce infarct size leading to improving outcomes (Jiang, Zuo, Wang, Lu, Yang, \& Wang, 2017).

Animal models of cerebral ischemia antioxidants reduce ROS-mediated activity and protect neurons from IR-induced neural loss (Mazza, Pomponi, Janiri, Bria, \& Mazz, 2007). In this regard, Anchusa italicah as antioxidant properties decreasing the level of oxidative stress and also possesses free radical scavenging activity (AlSnafi, 2014; Al-Snafi, 2015). This herb belongs to the Boraginaceae family and has been advocated as a folk medicine in temperate Mediterranean and Tropical regions. Phytochemical studies have revealed that A. Italica contains alkaloids, tannins, oil rich in vitamin $\mathrm{E}$, triterpenes, and polyphenols (Alsabri et al., 2012; Al-Snafi, 2015). It exhibits several pharmacological properties, including anticancer, antioxidant, antiviral, antimicrobial, hypotensive, and antidiabetic activities (Al-Snafi, 2014).

In this context, the use of traditional medicine is widespread and plants still represent a significant source of natural antioxidants. Consequently, the aim of this study was to evaluate the effect of a hydroalcoholic extract of A. italica, (HEAI) as a useful source of antioxidants on possible protection against global cerebral ischemia and reperfusion using an animal model. In particular, we focused on the involvement of the nitrosative stress pathway and up-regulation of the BDNF gene as the possible mechanism (Al-Snafi, 2014; Blondeau, Lipsky, Bourourou, Duncan, Gorelick, \& Marini, 2015).

\section{Methods}

2.1. Preparation of a hydro alcoholic extract of Anchusa italica

A. Italica was purchased from a medicinal herb supplier in Shahrekord and authenticated taxonomically by a senior plant taxonomist in the Medical Plants Research
Center, Shahrekord University of Medical Sciences. The flowers of A. italica were macerated with $70 \%$ ethanol at room temperature for one week. The extract was shaken, filtered, and evaporated in a rotary evaporator under reduced pressure for dryness. It was protected from light and stored at $4^{\circ} \mathrm{C}$ until tested and analyzed.

\subsection{Radical scavenging assay}

The antioxidant capability of HEAI was ascertained by the radical scavenging capacity for DPPH according to our previously established method. Accordingly, the IC50 values of HEAI were obtained for DPPH scavenging.

\subsection{Total phenolic compounds in HEAI}

The concentration of total phenolic compounds in HEAI was evaluated by an adapted Folin-Ciocalteu method described earlier.

\subsection{Total flavonoids in HEAI}

A colorimetric assay was employed to evaluate the total flavonoid content of HEAI. Total flavonoids were expressed in terms of Rutin equivalent (mg/g) (Molan \& Mahdy, 2014).

\subsection{Animals}

Male Wister rats weighing 250-300 g sourced from the Razi Institute (Tehran, Iran) were housed for a minimum of 7 days in an air-conditioned environment before testing. They were maintained in controlled conditions of room temperature $\left(25.0 \pm 3.0^{\circ} \mathrm{C}\right)$ and constant humidity $(10 \%)$, on an alternating $12 \mathrm{~h} / 12 \mathrm{~h}$ light/dark cycle and with ad libitum food plus water availability. The Ethics Committee of Shahrekord University of Medical Sciences approved the study (Ethics Code: IR.SKUMS. REC.1394.256).

\subsection{Global cerebral ischemia and preparation of experimental material}

Animals were assigned in a random fashion to four groups ( $\mathrm{n}=7$ ) as follows: 1. Sham-operated; 2. I-R (control), HEAI post-treatment at doses of; $3.50 \mathrm{mg} / \mathrm{kg}$ (AI50); and $4.100 \mathrm{mg} / \mathrm{kg}$ (AI-100) administered daily for 10 days, $24 \mathrm{~h}$ after I-R induction. Also, the animals in the sham-operated group were managed identically to controls; however, they underwent surgery without global cerebral artery occlusion (Torki et al., 2018).

In all four groups, the rats were weighed and anesthetized with an intraperitoneal (i.p.) injection of chloral hydrate (Merck, Germany) (400 mg/kg), and then 
a midline ventral incision was made in the neck. In the case of induced global cerebral ischemia, the bilateral carotid arteries were occluded by small artery clips. Sixty minutes after ischemia, reperfusion was performed by releasing the artery clips. In the shamoperated group, the arteries were exposed for $60 \mathrm{~min}$ without occlusion.

During surgery, the rectal temperature was maintained at $37^{\circ} \mathrm{C}$ by a heating pad. After reperfusion, animals were returned to their separate home cages. Twenty-four hours after surgery, AI-50 and AI-100 groups received 50 and $100 \mathrm{mg} /$ kg HEAI for 10 days via i.p. injection, respectively. Doses were chosen from previously published data. The control and sham-operated groups received normal saline instead of HEAI for 10 days. Subsequently, animals were weighed and anesthetized with chloral hydrate. Blood was collected from the abdominal aorta, and then serum was separated and stored at $-20^{\circ} \mathrm{C}$. The rats were decapitated, their brains were removed immediately, and both hippocampi were dissected on ice-cold plates. One lateral hippocampus was stored at $-70^{\circ} \mathrm{C}$ until the extraction of the mRNA content, whereas the other part was stored at $-20^{\circ} \mathrm{C}$ until it was used in the malondialdehyde (MDA) assay.

2.7. Determination of lipid peroxide content in rat plasma

The formation of Thiobarbituric Acid Reactive substances (TBARs) is used as an index of lipid peroxidation ascertained as MDA. This determination was carried out according to the method of Mihara and Uchiyama (Uchiyama \& Mihara, 1978). Thus, $100 \mu \mathrm{l}$ plasma or standard was mixed with 100 $\mu \mathrm{L}$ sodium dodecyl sulfate $(8.1 \%)$ and $2.5 \mathrm{ml}$ of Thiobarbituric Acid (TBA). The mixture was subsequently heated on a boiling water bath and the reaction was terminated $60 \mathrm{~min}$ later by placing the reaction tubes in ice. After centrifugation (4000 rpm x $10 \mathrm{~min}$ ), the absorbance of the supernatant was measured at $535 \mathrm{~nm}$ by a flow-through spectrophotometer.
2.8. Determination of lipid peroxide content in rat hippocampus

Brain tissues were homogenized in ice-cold Tris- $\mathrm{HCl}$ buffer $(0.05 \mathrm{~mol} / \mathrm{L}, \mathrm{Ph}=7.4)$ for $2 \mathrm{~min}$ at $5000 \mathrm{rpm}$. The homogenized solution was subsequently centrifuged at $4300 \mathrm{rpm}$ for $60 \mathrm{~min}$. Then, $100 \mu \mathrm{L}$ of the supernatant was mixed with $10 \mu \mathrm{L}$ butylated hydroxytoluene $(0.5 \mathrm{~mol} / \mathrm{L})$, $200 \mu \mathrm{L}$ sodium dodecyl sulfate $(8.1 \%)$ and $1.5 \mathrm{~mL}$ TBA. This suspension was heated for $60 \mathrm{~min}$ in a boiling water bath. After cooling, $3.0 \mathrm{~mL}$ of butanol-pyridine was added to the suspension and centrifuged at $3900 \mathrm{rpm}$ for $10 \mathrm{~min}$. The organic layer was transferred to a fresh tube and its absorbance was measured at $535 \mathrm{~nm}$ using a spectrophotometer (Karatas, Karatepe, \& Baysar, 2002).

\subsection{Nitric oxide assays}

Metabolites of NO in the serum were determined using the Griess reaction accompanied by the enzymatic reaction of nitrite and nitrate with copper-plated cadmium. Thus, the serum sample was deproteinated by adding $\mathrm{ZnSO} 4$ and $\mathrm{NaOH}$ solutions and activated cadmium granules were added to the pretreated deproteinated serum. Then, Griess reagents (sulfanilamide in 5\% chloric acid) plus N-[1-napthyl] ethylene diamine dihydrochloride) were added to the sample. Sample absorbance was then measured using a spectrophotometer set at $540 \mathrm{~nm}$. Concentrations of NO were measured based on a standard graph derived from a range of $\mathrm{NaNO} 3$ concentrations.

2.10. Quantitative analysis for eNOS, iNOS, and BDNF mRNA in hippocampal tissue using RealTime-PCR

Total RNA was isolated from hippocampal tissue using total RNA extracted with TRIzol reagent (Invitrogen, Carlsbad, CA, USA) adopting the manufacturer's recommended procedure.

Table 1. Primers used in qPCR for mRNAs

\begin{tabular}{|c|c|c|c|c|}
\hline Gene & $\begin{array}{l}\text { NCBI Accession } \\
\text { Number }\end{array}$ & Primer Sequence & $\begin{array}{l}\text { Annealing Temperature } \\
\qquad\left({ }^{\circ} \mathrm{C}\right)\end{array}$ & $\begin{array}{l}\text { PCR Product } \\
\text { (bp) }\end{array}$ \\
\hline iNOS & NM_012611.3 & $\begin{array}{l}\text { F:5- AACTACGTCCTATCTCCATTCTACT-3 } \\
\text { R: 5-AACACCGCTTTCACCAAGAC-3 }\end{array}$ & 58 & 125 \\
\hline eNOS & XM_006235872.1 & $\begin{array}{c}\text { F:5- AGCCCAAACACACAGAACCT-3 } \\
\text { R:5- AGCAGCACAAGAGTTACAAAATCC-3 }\end{array}$ & 59 & 145 \\
\hline BDNF & XM_006234684.3 & $\begin{array}{l}\text { F:5-ACGAGACCAAGTGTAATCCC-3 } \\
\text { R:5- GCCAATTCTCTTTTTGCTATCCAT-3 }\end{array}$ & 57.5 & 137 \\
\hline GPDH & NM_002046.7 & $\begin{array}{l}\text { F:5- GGTGGGGCCAAAAGGGTCAT-3 } \\
\text { R: 5- GGTTCACACCCATCACAAACAT-3 }\end{array}$ & 60 & 70 \\
\hline
\end{tabular}


Reverse transcription was performed on an aliquot containing $500 \mathrm{ng}$ of total RNA. The reaction was accomplished on the superscript first-strand cDNA synthesis system, based on the manufacturer's recommended procedure (Takara, Japan). The sequences of target genes and the specific primers are shown in Table 1.

BDNF, iNOS, and eNOS mRNA levels were measured using a Rotor-Gene 6000 real-time PCR cycler (Corbett, Australia). The Real-time PCR reaction was also performed on $1 \mu \mathrm{l}$ of synthesized cDNA solution, $5 \mu \mathrm{l}$ of SYBR Premix Ex Taq II (TliRNase H Plus) (Takara, Japan), and $0.2 \mu \mathrm{l}$ of each primer. Forty amplification cycles consisted of denaturation at $95^{\circ} \mathrm{C}$ for $15 \mathrm{~s}$, annealing according to Table 1 for $30 \mathrm{~s}$ and an extension at $72^{\circ} \mathrm{C}$ for $30 \mathrm{~s}$. Each sample was analyzed in triplicate. Glyceraldehyde-3-phosphate dehydrogenase (GAPDH) was utilized as a loading control to normalize target gene expression. Relative expression levels of the target $\mathrm{cD}$ NAs were quantified by the $2 \Delta \Delta$ Cts method.

\subsection{Statistical analysis}

Graph Pad software (San Diego, California, USA) was employed for data analysis. Statistical analysis of the data was performed employing the One-Way Analysis Of Variance (ANOVA) and Tukey post-hoc test to compare the differences between the control group and experimental groups $(\mathrm{P}<0.05$ was considered significant $)$.

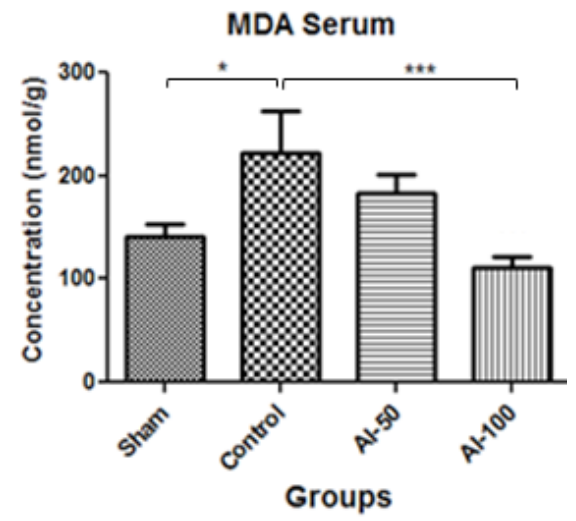

NEUR SCIENCE

Figure 1. Serum Malondialdehyde (MDA) concentrations measured in treatment groups in the global cerebral artery occlusion stroke model

The MDA level was diminished in the hydroalcoholic extract of Anchusa italica (100 mg/kg (AI-100))-treated group compared with the control group.

* Values are expressed as Mean \pm SEM

*** $\mathrm{P}<0.001$; $\mathrm{P}<0.05 ; \mathrm{n}=7$

\section{Results}

\subsection{Standardization of HEAI}

The total phenolic compound content in HEAI was $62.2 \pm 0.3 \mathrm{mg}$ gallic acid equivalent $/ \mathrm{g}$ of dried extract. Also, the total flavonoid compound content was $47.06 \pm 0.4 \mathrm{mg} / \mathrm{g}$ of dry matter.

\subsection{Antioxidant activity of HEAI}

The antioxidant activity of HEAI was evaluated using DPPH free radical scavenging and it possessed potent activity in this respect $\left(\mathrm{IC}_{50}=90.5 \pm 0.3 \mu \mathrm{g} / \mathrm{mL}\right)$.

\subsection{MDA content in rat serum after ischemia}

MDA levels in serum are shown in Figure 1. The MDA serum concentration in the global cerebral ischemia group was higher than the sham group and the MDA levels in the HEAI-treated groups decreased in a dose-dependent manner. HEAI, at the $100 \mathrm{mg} / \mathrm{kg}$ dose, significantly reduced $(\mathrm{P}<0.001)$ the MDA level than the controls.

\subsection{MDA content in rat hippocampus after ischemia}

MDA levels in the hippocampus are shown in Figure 2. In the ischemic group, there was an elevation in MDA in comparison with the sham-operated group. Administration of HEAI resulted in a significant reduction $(\mathrm{P}<0.01)$

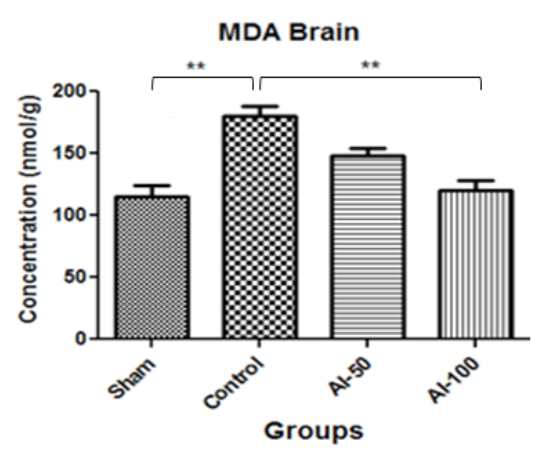

NEUR

Figure 2. Hippocampal tissue Malondialdehyde (MDA) concentrations measured in treatment groups in the global cerebral artery occlusion stroke model

The MDA levels decreased in the hydroalcoholic extract of Anchusa italica (100 mg/kg (AI-100))-treated group compared with the control group

*Values are expressed as Mean \pm SEM

** $\mathrm{P}<0.01 ; \mathrm{n}=7$ 


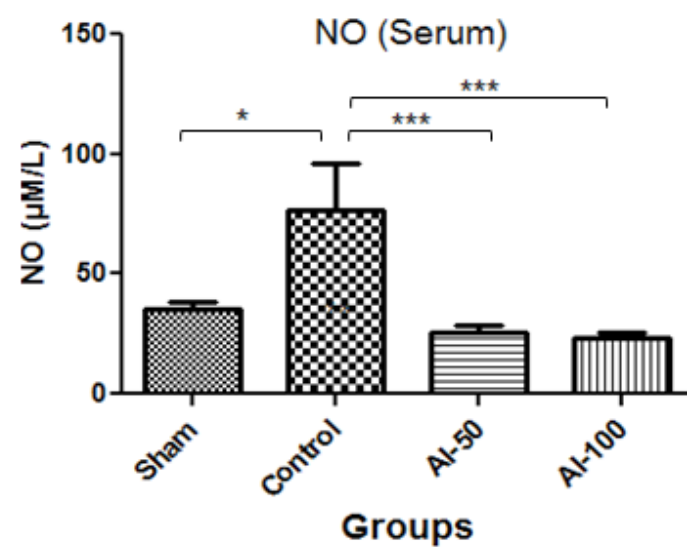

NEUR:SCIENCE

Figure 3. Nitric Oxide (NO) serum concentrations measured in treatment groups in the global cerebral artery occlusion stroke model

The levels of NO reduced in both groups treated with hydroalcoholic extract of Anchusa italica ( $50 \mathrm{mg} / \mathrm{kg}$ : AI-50 and $100 \mathrm{mg} / \mathrm{kg}$ : AI-100) compared with the control group.

*Values are expressed as Mean \pm SEM.

*** $\mathrm{P}<0.001 ; * \mathrm{P}<0.05 ; \mathrm{n}=7$

in lipid peroxidation (plasma MDA levels) at the 100 $\mathrm{mg} / \mathrm{kg} /$ day dose $(\mathrm{P}<0.01)$ when compared with the control group. No significant difference in plasma MDA levels was observed between the AI-100 and AI-50 groups.

\subsection{NO content in rat serum after ischemia}

NO levels in the serum are shown in Figure 3. In the animal control group, there was a significantly higher level of NO compared with the sham-operated group (76.26 $\mu \mathrm{M} / \mathrm{L}$ and $35.25 \mu \mathrm{M} / \mathrm{L}$, respectively). The $\mathrm{NO}$ concentrations in the HEAI-treated groups decreased in comparison with controls; however, there was no significant difference $(\mathrm{P}<0.001)$ between NO levels in the AI50 and AI-100 treatment groups $(25.76 \mu \mathrm{M} / \mathrm{L}$ and 23.59 $\mu \mathrm{M} / \mathrm{L}$, respectively).

3.6. iNOS and eNOS mRNA expression in the hippocampus after ischemia

Global cerebral ischemia caused a decrease in iNOS mRNA expression in the sham-operated animals compared with the controls $(\mathrm{P}<0.001)$. Furthermore, HEAI at the doses of $50 \mathrm{mg} / \mathrm{kg}$ and $100 \mathrm{mg} / \mathrm{kg}$ both reduced the iNOS mRNA signal in the hippocampus compared with the control group $(\mathrm{P}<0.001)$; however, there was no difference in the reduction of iNOS mRNA between these two doses. However, the administration of HEAI produced an upward trend in eNOS mRNA expression in the hippocampus but it was not statistically significant and there was no difference between the effects of the two treatment groups (AI-50 and AI-100) $(\mathrm{P}<0.05)$ (Figure 4).

\subsection{BDNF mRNA expression in the hippocampus} after ischemia
iNOS

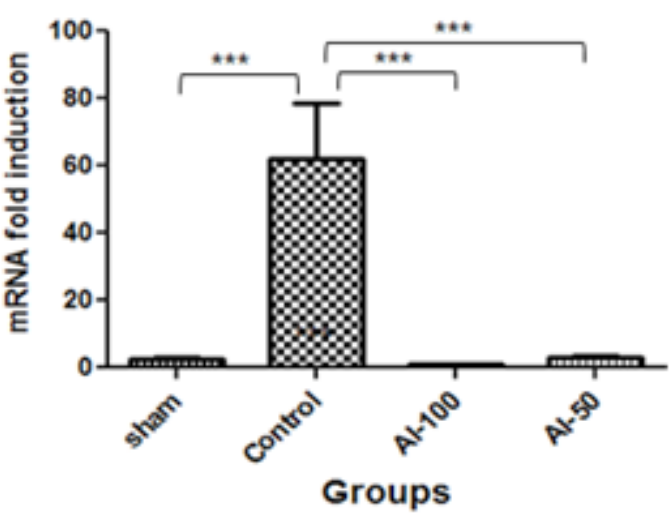

eNOS

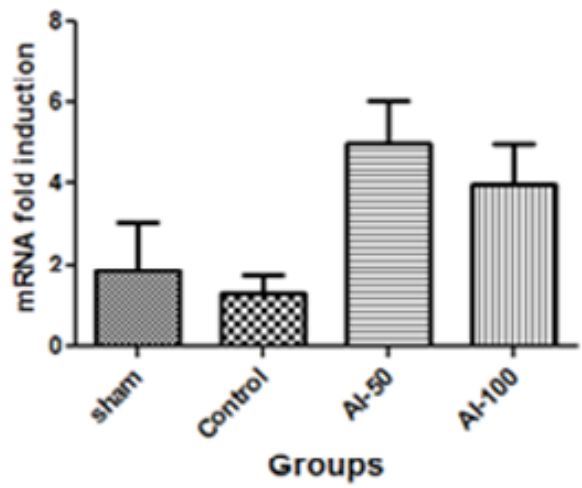

NEUR: $S$ CIENCE Figure 4. Fold-change in hippocampal tissue iNOS and eNOS mRNA expression in the global cerebral artery occlusion stroke model

The iNOS mRNA expression level decreased in both groups treated with Hydroalcoholic Extract Of Anchusa Italica (HEAI) (50 mg/kg: AI-50 and 100 mg/kg: AI-100) compared with the control group.

The eNOS mRNA expression level displayed an increasing trend in both HEAI-treated groups (AI-50 and AI-100) in comparison with the control group;

*Values are expressed as Mean \pm SEM;

$* * * 00.001 ; \mathrm{n}=7$ 


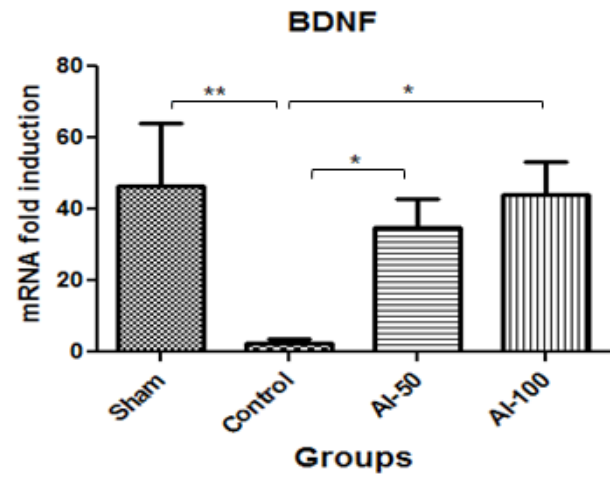

NEUR SCIENCE

Figure 5. Fold-change in hippocampal tissue BDNF mRNA expression in the global cerebral artery occlusion stroke model

The BDNF mRNA expression level increased in both hydroalcoholic extract of Anchusa italic-treated groups (50 mg/kg: AI-50 and $100 \mathrm{mg} / \mathrm{kg}$ : AI-100) compared with the control group;

* Values are expressed as Mean \pm SEM

** $\mathrm{P}<0.01 ; * \mathrm{P}<0.05 ; \mathrm{n}=7$

Global cerebral ischemia resulted in significantly reduced BDNF mRNA hippocampal expression in the control group compared with sham-operated animals $(\mathrm{P}<0.01)$. HEAI at the doses of 50 and $100 \mathrm{mg} / \mathrm{kg}$ both increased the BDNF mRNA signal in the hippocampus than controls; however, no difference was observed between the treated groups (A-50 and AI-100; $(\mathrm{P}<0.05)$ (Figure 5).

\section{Discussion}

This is the first report regarding a protective propensity of HEAI against global cerebral ischemia and reperfusion in an animal model via inhibition of the nitrosative stress pathway and up-regulation of the BDNF gene. During the breakdown of lipid hydroperoxides, MDA is formed. It is an established biomarker of free radical damage in pathologies related to oxidative stress. In the first phase of our study, we showed that post-cerebral ischemic treatment of rats with HEAI, at the doses of 50 and $100 \mathrm{mg} / \mathrm{kg}$, caused a significant decrease in MDA levels not only in serum but also in hippocampal brain tissue. HEAI at the higher dose appeared to be more effective than the lower dose (Figure $1)$.

In agreement with these findings, there are other reports concerning the modulatory effect of Borago officinales (Boraginaceae family) on lipid peroxidation in the hippocampus (Ghahremanitamadon, Shahidi, Zargooshnia, Nikkhah, Ranjbar, \& Soleimani Asl, 2014). Besides, our results showed that the NO content in serum substantially decreased in the HEAI-treated animals compared with the I-R group, but this effect was not dose-dependent. Endogenous NO is generated by the NOS enzyme group. It has a wide range of physiological and pathophysiological actions and there are three NOS isoforms in the enzyme family, which are capable of producing NO (Blanco, Hernández, Franchelli, Ramos-Álvarez, \& Peinado, 2017). NOS1 or neuronal NOS (nNOS) is constitutively expressed in neurons in the brain. NOS2 or inducible NOS (iNOS), is not present under normal physiological conditions but is produced in response to immunological stimulation. NOS3 or endothelial NOS (eNOS) has an important vasodilatory function and is constitutively expressed in brain endothelial cells (Blanco et al., 2017).

Endogenous NO released from nitrergic neurons regulates the release of several monoamine neurotransmitters, excitatory and inhibitory amino acids, and adenosine (Prast \& Philippu, 2001). Furthermore, NO is not only a neuromodulator of neurotransmitter and neuropeptide function presynaptically but it also promotes synaptic plasticity. In addition, it is implicated in both short- and long-term memory in the hippocampus. In physiological conditions, NO activates soluble guanylate cyclase (sGC) producing cyclic guanosine monophosphate (cGMP). The NO/GC pathway is involved in hippocampal long-term memory formation and it has been shown that NOS inhibitors block long-term potentiation (Prast \& Philippu, 2001).

NO either has a protective or detrimental influence on ischemic brain injury, which depends on the NOS isoform source and the cell type (Pluta, 2005). In our study, we discovered that iNOS mRNA was induced in hippocampal tissue following cerebral ischemia. Treatment with HEAI suppressed iNOS mRNA expression, which may conceivably be responsible for protective effects against ischemic stroke. Overexpression of NO from iNOS leads to neurodegeneration approved by a reduction in brain infarct volume and edema in iNOS knockout mice after transient focal ischemic injury (Hara, Huang, Panahian, Fishman, \& Moskowitz, 1996).

We also observed that iNOS mRNA was overexpressed in hippocampal tissue as a result of cerebral ischemia, but after HEAI treatment, this overexpression was completely abolished. Although NO has positive effects, if its production becomes uncontrollably perturbed, this may be significantly harmful as a consequence of initiating neurotoxicity and apoptosis. In this context, NO and its superoxide combination product, peroxynitrite, have been reported to be conducive to the pathogenesis of neurodegenerative conditions (Anaeigoudari, Soukhtanloo, Reisi, Beheshti \& Hosseini, 2016). 
NO has been demonstrated to incite DNA fragmentation through a mitochondrial apoptotic pathway (Wang et al., 2010). It can also instigate oxidative DNA damage and break single-stranded DNA-triggering cellular injury through activation of poly (ADP-ribose) polymerase, a nuclear enzyme that depletes essential substrates and potentially contributes to neurotoxicity (Blanco et al., 2017). In this regard, iNOS expression may play a pathogenic role in the mechanisms of cerebral ischemic damage.

Treatment with HEAI displayed a trend towards upregulation of eNOS mRNA expression in hippocampal tissue after global cerebral ischemic injury. Moreover, eNOS-deficient mice have been shown to exhibit a marked impairment of angiogenesis and increased infarct volume in the ischemic brain. In contrast, overexpressed eNOS in transgenic mice renders them resistant to stressinduced hypotension, inflammation, and stroke (Beck \& Plate, 2009). It is well established that global ischemia, caused by reduced cerebral blood flow, initiates a cascade of mechanisms, including elevated levels of ROS, excitotoxicity, mitochondrial dysfunction and neuronal apoptosis (Tóthová, Kovalská, Kalenská, Tomašcová, \& Lehotský 2018). Accordingly, eNOS has a neuroprotective role by increasing blood flow in the very early stages of cerebral ischemia (Hashiguchi et al., 2004).

BDNF expression is regulated by NO generated from eNOS in the brain (Cao et al., 2011). This highlights the potentially important role of neuronally-derived eNOS in modulating BDNF production and the need for further investigation of any favorable propensity of eNOS on neuronal survival following stroke. In this respect, eNOS-knockout-mice have shown a reduced expression of BDNF in the ischemic brain (Chen et al., 2005) and it has been postulated that a deficiency of eNOS associated with down-regulated BDNF expression, impairs neurogenesis after stroke. NO and BDNF appear to operate in a positive feedback loop promoting neurogenesis and eNOS may be a noteworthy target gene in new therapeutic approaches for central ischemia.

Our results showed that treatment with HEAI significantly up-regulated the expression of BDNF mRNA in brain tissue after ischemic injury. Furthermore, inhibition of NOS activity reduces the de novo synthesis of NO, leading to a decline in BDNF (Faraco et al., 2018) and this concurs with our observed down-regulated hippocampal BDNF mRNA expression in the I-R control group.

A. italic contains alkaloids, tannins, essential oils, triterpenes and polyphenols that possess antioxidant properties, and it is regarded as one of the best sources of $\gamma$-linolenic acid (GLA) and $\alpha$-linolenic acid (ALA) (Conforti et al., 2011; Al-Snafi, 2014). ALA, in particular, is known to have beneficial effects on brain ischemia and post-stroke depression (Blondeau et al., 2015) and ALA increases BDNF mRNA and protein levels during cerebral ischemia. Additionally, recent studies have shown that ALA can increase neurogenesis, synaptogenesis, and synaptic function in the brain (Blondeau et al., 2015), which can be a useful characteristic in stroke.

It was observed that the administration of an A. italic extract decreased the levels of lipid peroxidation product, MDA, as a marker of oxidative stress. This suggested that A. italica reduces oxidative stress in global cerebral I-R injury. We also demonstrated that HEAI down-regulated iNOS mRNA expression induced an upward trend in eNOS mRNA, and up-regulated BDNF expression, which may be beneficial in the ischemic brain.

\section{Ethical Considerations}

\section{Compliance with ethical guidelines}

All ethical principles were considered in this article. The study protocol was approved by the Ethics Committee of Shahrekord University of Medical Sciences (Ethics code: IR.SKUMS.REC.1394.256).

\section{Funding}

This research was financially supported by the Research Deputy of Shahrekord University of Medical Sciences, Shahrekord, Iran (Grant No.: 2052).

\section{Authors' contributions}

Conceptualization, formal analysis, and writing the draft: Samira Asgharzade; Investigation and writing the draft: Samira Asgharzade; Data acquisition and methodology: Samira Asgharzade, Zahra Rabiei, and Sedigheh Kazemi Sheikhshabani; Review and editing: Robert D. E. Sewell; Supervision and project administration: Mahmoud Rafieian-Kopaei; Acquisition of funding: Mahmoud Rafieian-Kopaei.

\section{Conflict of interest}

The authors declared no conflicts of interest. The authors alone are responsible for the content and writing of the article. 


\section{Acknowledgments}

The authors would like to offer their special appreciation to the Research Deputy of Shahrekord University of Medical Sciences, Shahrekord, Iran for financial support of this research.

\section{References}

Alsabri, S. G., Zetrini, A. E., Ermeli, N. B., Mohamed, S. B., Bensaber, S. M., \& Hermann, A., et al. (2012). Study of eight medicinal plants for antioxidant activities. Journal of Chemical and Pharmaceutical Research, 4(8), 4028-31. https://www.researchgate.net/publication/233759560

Al-Snafi, A. E. (2014). The pharmacology of Anchusa italica and Anchusa strigosa. A review. International Journal of Pharmacy and Pharmaceutical Sciences, 6(4), 7-10. https:/ / www.researchgate.net/publication/267033194

Al-Snafi, A. E. (2015). Therapeutic properties of medicinal plants: A review of plants with antioxidant activity (part 1). International Journal of Pharmacy \& Therapeutics, 6(3), 159-82. https://www.researchgate.net/publication/313696720

Anaeigoudari, A., Soukhtanloo, M., Reisi, P., Beheshti F., \& Hosseini, M. (2016). Inducible nitric oxide inhibitor aminoguanidine, ameliorates deleterious effects of lipopolysaccharide on memory and long term potentiation in rat. Life Sciences, 158, 22-30. [DOI:10.1016/j.lfs.2016.06.019] [PMID]

Asgharzade, S., Rabiei Z., \& Rafieian-Kopaei, M. (2015). Effects of Matricaria chamomilla extract on motor coordination impairment induced by scopolamine in rats. Asian Pacific Journal of Tropical Biomedicine, 5(10), 829-33. [DOI:10.1016/j.apjtb.2015.06.006]

Asgharzade, S., Rafieian-Kopaei, M., Mirzaeian, A., Reiisi, S., \& Salimzadeh, L. (2015). Aloe vera toxic effects: Expression of inducible Nitric Oxide Synthase (iNOS) in testis of wistar rat. Iranian Journal of Basic Medical Sciences, 18(10), 967-73. [PMID] [PMCID]

Bart van der Worp, H., \& van Giin, J. (2007). Acute ischemic stroke. The New England Journal of Medicine, 357(6), 572-9. [DOI:10.1056/NEJMcp072057] [PMID]

Beck, H., \& Plate, K. H. (2009). Angiogenesis after cerebral ischemia. Acta Neuropathologica, 117(5), 481-96. [DOI:10.1007/ s00401-009-0483-6] [PMID]

Blanco, S., Hernández, R., Franchelli, G., Ramos-Álvarez, M. M., \& Peinado, M. Á. (2017). Melatonin influences NO/NOS pathway and reduces oxidative and nitrosative stress in a model of hypoxic-ischemic brain damage. Nitric Oxide, 62, 3243. [DOI:10.1016/j.niox.2016.12.001] [PMID]

Blondeau, N., Lipsky, R. H., Bourourou, M., Duncan, M. W., Gorelick, P. B., \& Marini, A. M. (2015). Alpha-linolenic acid: An omega-3 fatty acid with neuroprotective properties-ready for use in the stroke clinic? BioMed Research International, 2015, 519830. [DOI:10.1155/2015/519830] [PMID] [PMCID]

Cao, Y., Mao, X., Sun, C., Zheng, P., Gao, J., \& Wang, X, et al. (2011). Baicalin attenuates global cerebral ischemia/ reperfusion injury in gerbils via anti-oxidative and antiapoptotic pathways. Brain Research Bulletin, 85(6), 396-402 [DOI:10.1016/j.brainresbull.2011.05.002] [PMID]

Chen, J., Cui, X., Zacharek, A., Roberts, C., \& Chopp, M. (2009). eNOS mediates TO90317 treatment-induced angiogenesis and functional outcome after stroke in mice. Stroke, 40(7) 2532-8. [DOI:10.1161/STROKEAHA.108.545095] [PMID] [PMCID]

Chen, J., Zacharek, A., Zhang, C., Jiang, H., Li, Y., \& Roberts, C., et al. (2005). Endothelial nitric oxide synthase regulates brainderived neurotrophic factor expression and neurogenesis after stroke in mice. The Journal of Neuroscience, 25(9), 2366-75. [DOI:10.1523/JNEUROSCI.5071-04.2005] [PMID] [PMCID]

Chen, M. J., Ivy, A. S., \& Russo-Neustadt, A. A. (2006). Nitric oxide synthesis is required for exercise-induced increases in hippocampal BDNF and phosphatidylinositol 3' kinase expression. Brain Research Bulletin, 68(4), 257-68. [DOI:10.1016/j. brainresbull.2005.08.013] [PMID]

Conforti, F., Marrelli, M., Carmela, C., Menichini, F., Valentina, P., \& Uzunov, D., et al. (2011). Bioactive phytonutrients (omega fatty acids, tocopherols, polyphenols), in vitro inhibition of nitric oxide production and free radical scavenging activity of non-cultivated Mediterranean vegetables. Food Chemistry, 129(4), 1413-9. [DOI:10.1016/j.foodchem.2011.05.085]

Cui, X., Chopp, M., Zacharek, A., Ning, R., Ding, X., \& Roberts, C., et al. (2013). Endothelial nitric oxide synthase regulates white matter changes via the BDNF/TrkB pathway after stroke in mice. PLoS One, 8(11), e80358. [DOI:10.1371/journal. pone.0080358] [PMID] [PMCID]

Faraco, G., Wang, G., Santisteban, M. M., Chang, H., Segarra S., \& Anrather, J., et al. (2018). Abstract TMP94: Dietary salt impairs cognitive function through suppression of endothelial nitric oxide synthesis and hippocampal BDNF signaling. Stroke, 49(Suppl_1), ATMP94. [DOI:10.1161/str.49.suppl_1. TMP94]

Ghahremanitamadon, F., Shahidi, S., Zargooshnia, S., Nikkhah, A., Ranjbar, A., \& Soleimani Asl, S. (2014). Protective effects of Borago officinalis extract on amyloid $\beta$-peptide (25-35)-induced memory impairment in male rats: A behavioral study. BioMed Research International, 2014, 798535. [DOI:10.1155/2014/798535] [PMID] [PMCID]

Hara, H., Huang, P. L., Panahian, N., Fishman, M. C., \& Moskowitz, M. A. (1996). Reduced brain edema and infarction volume in mice lacking the neuronal isoform of nitric oxide synthase after transient MCA occlusion. Journal of Cerebral Blood Flow and Metabolism, 16(4), 605-11. [DOI:10.1097/00004647199607000-00010] [PMID]

Harooni, H. E., Naghdi, N., Sepehri, H., \& Haeri Rohani, A. (2009). The role of hippocampal Nitric Oxide (NO) on learning and immediate, short- and long-term memory retrieval in inhibitory avoidance task in male adult rats. Behavioural Brain Research, 201(1), 166-72. [DOI:10.1016/j.bbr.2009.02.011] [PMID]

Hashiguchi, A., Yano, S., Morioka, M., Hamada, J., Ushio, Y., \& Takeuchi, Y., et al. (2004). Up-regulation of endothelial nitric oxide synthase via phosphatidylinositol 3-kinase pathway contributes to ischemic tolerance in the CA1 subfield of gerbil hippocampus. Journal of Cerebral Blood Flow and Metabolism 24(3), 271-9. [DOI:10.1097/01.WCB.0000110539.96047.FC] [PMID] 
Jiang, C., Zuo, F., Wang, Y., Lu, H., Yang,Q., \& Wang, J. (2017). Progesterone changes VEGF and BDNF expression and promotes neurogenesis after ischemic stroke. Molecular Neurobiology, 54(1), 571-81. [DOI:10.1007/s12035-015-9651-y] [PMCID]

Karatas, F., Karatepe, M., \& Baysar, A. (2002). Determination of free malondialdehyde in human serum by high-performance liquid chromatography. Analytical Biochemistry, 311(1), 76-9. [DOI:10.1016/S0003-2697(02)00387-1]

Liu, H., Li, J., Zhao, F., Wang, H., Qu, Y., \& Mu, D. (2015). Nitric oxide synthase in hypoxic or ischemic brain injury. Reviews in the Neurosciences, 26(1), 105-17. [DOI:10.1515/revneuro-2014-0041] [PMID]

Mazza, M., Pomponi, M., Janiri, L., Bria, P., \& Mazza, S. (2007) Omega- 3 fatty acids and antioxidants in neurological and psychiatric diseases: An overview. Progress in Neuro-Psychopharmacology and Biological Psychiatry, 31(1), 12-26. [DOI:10.1016/j. pnpbp.2006.07.010] [PMID]

Molan, A. L., \& Mahdy, A. S. (2014). Iraqi medicinal plants: Total flavonoid contents, free-radical scavenging and bacterial beta-glucuronidase inhibition activities. IOSR Journal of Dental and Medical Sciences, 13(5), 72-7. [DOI:10.9790/0853-13527277]

Paul, V., \& Ekambaram, P. (2011). Involvement of nitric oxide in learning \& memory processes. Indian Journal of Medical Research, 133(5), 471-8. [PMID] [PMCID]

Peng, B., Guo, Q. L., He, Z. J., Ye, Z., Yuan, Y. J., \& Wang, N., et al. (2012). Remote ischemic postconditioning protects the brain from global cerebral ischemia/reperfusion injury by up-regulating endothelial nitric oxide synthase through the PI3K/ Akt pathway. Brain Research, 1445, 92-102. [DOI:10.1016/j. brainres.2012.01.033] [PMID]

Pluta, R. M. (2005). Delayed cerebral vasospasm and nitric oxide: Review, new hypothesis, and proposed treatment Pharmacology \& Therapeutics, 105(1), 23-56. [DOI:10.1016/j. pharmthera.2004.10.002] [PMID]

Prast, H., \& Philippu, A. (2001). Nitric oxide as modulator of neuronal function. Progress in Neurobiology, 64(1), 51-68. [DOI:10.1016/S0301-0082(00)00044-7]

Prentice, H., Modi, J. P., \& Wu, J. Y. (2015). Mechanisms of neuronal protection against excitotoxicity, endoplasmic reticulum stress, and mitochondrial dysfunction in stroke and neurodegenerative diseases. Oxidative Medicine and Cellular Longevity, 2015, 964518. [DOI:10.1155/2015/964518] [PMID] [PMCID]

Smith, A. E., Xu, Z., Lai, Y. Y., Kulkarni, P. M., Thakur, G. A., \& Hohmann, A. G., et al. (2016). Source memory in rats is impaired by an NMDA receptor antagonist but not by PSD95nNOS protein-protein interaction inhibitors. Behavioural Brain Research, 305, 23-9. [DOI:10.1016/j.bbr.2016.02.021] [PMID] [PMCID]

Torki, A., Khalaji-Pirbalouty, V., Lorigooini, Z., Rafieian-Kopaei, M., Sadeghimanesh, A., \& Rabiei, Z. (2018). Anchusa italica extract: Phytochemical and neuroprotective evaluation on global cerebral ischemia and reperfusion. Brazilian Journal of Pharmaceutical Sciences, 54(1), e17251. [DOI:10.1590/s217597902018000117251]

Tóthová, B., Kovalská, M., Kalenská, D., Tomašcová, A., \& Lehotský, J. (2018). Histone hyperacetylation as a response to global brain ischemia associated with hyperhomocysteinemia in rats. International Journal of Molecular Sciences, 19(10), 3147. [DOI:10.3390/ijms19103147] [PMID] [PMCID]

Uchiyama, M., \& Mihara, M. (1978). Determination of malonaldehyde precursor in tissues by thiobarbituric acid test Analytical Biochemistry, 86(1), 271-8. [DOI:10.1016/00032697(78)90342-1]

Wang, W., Xu, J., Li, L., Wang, P., Ji, X., \& Ai, H., et al. (2010). Neuroprotective effect of morroniside on focal cerebral ischemia in rats. Brain Research Bulletin, 83(5), 196-201. [DOI:10.1016/j. brainresbull.2010.07.003] [PMID]

Zeng, X. W., Li, M. W., Pan, J., Ji, T. L., Yang, B., \& Zhang, B. et al. (2011). Activation of c-Jun $\mathrm{N}$-terminal kinase $1 / 2$ regulated by nitric oxide is associated with neuronal survival in hippocampal neurons in a rat model of ischemia. Chinese Medical Journal, 124(20), 3367-72. [DOI:10.3760/cma.j.is sn.0366-6999.2011.20.029] [PMID] 